\title{
Comparison of Radiation Doses between 64-slice Single Source and 128-slice Dual Source CT Coronary Angiography in patient
}

\author{
Yeonghan Kang
}

Department of Diagnostic Radiology, Daegu Catholic University Hospital

\section{4-slice single source CT와 128-slice dual source CT를 이 용한 관상동맥 조영 검사 시 환자선량 비교}

강영한

대구가톨릭대학교병원 영상의학과

\begin{abstract}
The purpose of this study was to estimate radiation doses from 64-slice single source Computed Tomography(SSCT) coronary angiography(CA) and 128-slice dual source Computed Tomography(DSCT). With SSCT CA, the effective dose averaged approximately $13.86 \mathrm{mSv}$ when two dose modulation was not. The mean effective dose for DSCT CA with retrospectively gated helical(RGH) technique was $11.87 \mathrm{mSv}$, when prospective ECG gating transverse(PGT) without dose modulation technique was $5.61 \mathrm{mSv}$. The one with dose modulation in PGT technique and flash mode were $3.04 \mathrm{mSv}$ and flash mode was $0.98 \mathrm{mSv}$ respectively. The lifetime attributable risk(LAR) of cancer incidence from SSCT RGH mode averaged approximately 1 for 1,176, and DSCT averaged 1 for 1,960(RGH mode), 1 for 3,030(PGT without modulation), 1 for 5,882(PGT with modulation). Because of CTCA is associated with non-negligible risk of cancer. Doses can be reduced by application PGT, FLASH than RGH using DSCT.
\end{abstract}

Key Words : 64-slice single source CT, 128-dual source CT, Effective dose, Lifetime attributable risk

\section{요야}

본 연구는 64 -절편 단선원 $\mathrm{CT}(\mathrm{SSCT})$ 와 128 -절편 이중선원(DSCT)을 이용한 관상동맥조영 CT 검사 시 방사선 량에 대해 알아보고, 이 선량으로 인한 암 발생의 잠재적 위험(LAR)을 평가해 보았다. SSCT의 후향적동조화(RGH) 스캔의 유효선량은 $13.86 \mathrm{mSv}$ 이었고, $\mathrm{DSCT}$ 의 $\mathrm{RGH}$ 스캔의 유효선량은 $11.87 \mathrm{mSv}$ 이었다. DSCT의 전향적동조화 (PGT) 스캔 중 선량변조를 적용치 않은 모드의 유효선량은 $5.61 \mathrm{mSv}$, 선량변조를 적용하였을 때는 $3.04 \mathrm{mSv}$ 이었 다. 1 회 스캔하는 FLASH 모드는 $0.98 \mathrm{mSv}$ 이었다. SSCT의 RGH 스캔의 LAR은 1,176 명 중 1 명, DSCT의 RGH에서 는 1,960 명 중 1 명이었다. DSCT의 PGT는 3,030 명 중 1 명, 선량변조를 하면 5,882 명 중 1 명에서 발암 위험이 있었다. 따라서 SSCT와 DSCT를 이용한 관상동맥조영 CT 검사는 암발생 귀속위험과 관련성이 있음을 인지하여야 하고, 환자 선량을 줄이기 위해 RGH보다 PGT, FLASH 등의 프로토콜을 적용하는 것이 필요하다.

중심단어: 64단선원 CT, 128 이중선원 CT, 유효선량, 암발생귀속위험 


\section{I. 서론}

다중 절편 전산화단층촬영(multi-slice computed tomography, 이하 MSCT)을 이용한 비침습적인 관상동 맥조영술(coronary angiography, 이하 CTCA)은 관상동맥 질환(coronary artery disease, 이하 $\mathrm{CAD}$ )의 정확한 진단 과 평가를 위한 중요한 임상적 도구이다 ${ }^{[1,2]}$. 64-절편 단선원 $\mathrm{CT}$ (64-slice single source computed tomography, 이하 SSCT)와 128-절편 이중선원 $\mathrm{CT}(128$-slice dual source computed tomography, 이하 DSCT)의 도입으로 인해 관상동맥 질환의 진단에 CT 영상검사가 아주 유 용하게 사용되고 있고, 검사의 편리성으로 인해 검사 건수는 지속으로 늘어나고 있으며 그로 인한 피폭선 량도 증가하고 있다 ${ }^{[3]}$. DSCT는 2 개의 선관과 2 개의 검 출기 부분으로 특징되어지고, 이들은 갠트리가 회전할 때 서로 수직으로 움직인다. 이 스캐너는 $75 \mathrm{~ms}$ 의 빠 른 시간분해능을 제공하기 때문에 DSCT의 CTCA는 높은 심박율에서도 진단적 가치가 충분히 있는 영상 을 제공할 수 있게 되었고, 또한 심박율의 조정이 없 이도 민감도, 특이도, 양성예측도 및 음성예측도는 각 각 $96.4,97.5,85.7,99.4 \%$ 로 높게 나타난다 ${ }^{[4-6]}$. 하지만 $\mathrm{DSCT}$ 의 CA가 CAD를 평가하는데 임상적 유용성은 높지만 방사선 노출에 따른 잠재적 발암 위험에 대해 서는 여전히 간과할 수 없는 부분이다.

심장 CT 검사는 심전도 동조화(ECG gating) 상태에 서 시행하며, 전향적 동조화(prospective ECG gating transverse, 이하 PGT)와 후향적 동조화 기법 (retrospective ECG gating helical, 이하 RGH)이 있다. $\mathrm{PGT}$ 스캔은 심장 주기의 R파가 검출되면 정해진 촬영 시작 지연시간(scan delay time)을 정하여 스캔을 시작하 는 방법으로 촬영 테이블을 순차적으로 이동시키며, 나선형 촬영(spiral scan)이 아닌 순차적 촬영(sequential $\mathrm{scan})$ 을 한다. RGH 스캔이란 심전도를 기록하며, 심장 주기에 상관없이 연속적으로 촬영한 후 기록되어 있는 심전도를 이용하여 일정 시점의 심장 주기에서 영상을 재구성하는 것을 말한다. 이를 위하여 갠트리 1 회전 당 절편 총 두께와 테이블 이동비로 표현되는 피치(pitch) 를 작게 하여 중복되는 데이터를 얻어야만 원하는 심 장 주기의 완전한 심장영상을 얻을 수 있다. 전체 심장
주기 동안 방사선 노출이 적용되는 RGH 스캔과 비교 해 보면, PGT 스캔은 미리 지정해 놓은 심장 주기에만 방사선이 노출되기 때문에 지정하지 않는 잔여의 심장 주기 동안은 방사선의 노출이 되지 않아 결국 방사선 량의 감소를 가져올 수 있다는 원리이다. 실제로 SSCT 를 이용한 RGH 스캔의 경우 유효선량이 18.4-21.1 mSv 이었지만, PGT 스캔은 2.8-5 mSv까지 선량을 줄일 수 있다고 하였다 ${ }^{[7-12]}$. 이러한 선량이 인체에 미치는 영향 은 미국 $\mathrm{FDA}$ 에서 심장 $\mathrm{CT}$ 스캔으로 인한 피폭선량이 $10 \mathrm{mSv}$ 이면 대략 2,000 명 중 1 명이 치명적 암의 발생 가능성이 있다고 보고하여 CT로 인한 잠재적 발암위 험을 경고하였다 ${ }^{[13]}$.

본 연구는 최근 개발되어 상용화 된 128-절편 DSCT의 $\mathrm{CA}$ 검사 시 프로토콜에 따른 선량을 알아보고, 64-절편 $\mathrm{SSCT}$ 의 RGH 기법의 선량과 차이를 비교하였으며, BEIR VII을 이용하여 발암 위험을 평가해 보고자 하였다.

\section{II. 대상 및 방법}

모든 환자들은 관상동맥 질환이 의심되거나 관상동 맥질환을 않고 있는 사람이었고, 임상적 원인을 찾기 위해 CTCA를 시행하였다. 각 스캔의 유효선량 산출 시 칼슘수치화(calcium scoring)는 배제하였다.

\section{64-절편 $\mathrm{SSCT}$ 관상동맥 조영 스캔}

2010년 10 12월까지 3개월 동안 64-절편 SSCT(GE, Lightspeed VCT, USA)를 이용해서 CA를 시행한 128 명 (남자 68명, 여자 60명; 평균 연령 60.2세)을 대상으로 하였다. 신장과 체중을 바탕으로 한 체질량지수의 평 균은 $23.4 \mathrm{~kg} / \mathrm{m}^{2}$ 이었다. 대상자는 모두 최소 6시간 금 식한 상태에서 RGH mode로 스캔을 하였다. 관상동맥 조영 검사를 위해 사용되는 표준 프로토콜 $(64 \times 0.625$ $\mathrm{mm}$ slice collimation, $0.35 \mathrm{sec}$ rotation time(cine mode), 120 $\mathrm{kVp}$ tube voltage, $400 \mathrm{~mA}$ tube current)을 이용하여 영 상을 획득하였으며, 관전류 변조(tube current modulation)는 적용하지 않았다. 심박수가 70 회/min 이 상인 경우 atenolol 25-75 mg을 촬영 1시간 전에 복용하 였고, 니트로글리세린 설하정 $0.6 \mathrm{mg}$ 을 촬영 1 분 전에 투여하였다. 자동주입기를 이용하여 조영제(Iopromide, Ultravist $370 \mathrm{mg}$ I/mL; Schering AG, Berlin, Germany)를 
초당 $5.0 \mathrm{~m} \ell$ 로 총 $60 \mathrm{~m} \ell$ 를 정주한 후 같은 속도로 생 리식염수를 $40 \mathrm{~m} \ell$ 를 추가로 전완동맥을 통해 주입하였 다. 모든 환자에서 $z$ 축 방향으로 기관 분지부에서 심 장 기저부까지 스캔하였으며, 검사 시작은 주폐동맥 위치의 하행대동맥에서 ROI를 설정한 후 CT number 가 $100 \mathrm{HU}$ 에 도달한 시간부터 7초 후 주폐동맥 분기 부 중앙부위에서 횡격막까지 한 번의 호흡으로 시행 하였다. 영상 획득 시 함께 기록된 심전도에 따라 multi-segment algorithm을 이용하여 이완중기 (mid-diastolic phase, $75 \%$ of R-R interval)에 영상을 재구 성하였다.

\section{128-절편 DSCT 관상동맥 조영 스캔}

2011년 2 6월까지 5개월 동안 128-절편 DSCT 기기 (Somatom Definition ${ }^{\circledR}$; Siemens Healthcare, Forchheim, Germany)를 이용하여 CTCA 검사를 시행한 314명(남자 170 명, 여자 144명; 평균 연령 61.7세)을 대상으로 하였 다. 검사준비와 과정은 SSCT와 동일하였고, 스캔 전에 베타 차단제는 복용하지 않았다. 관상동맥 조영 검사 를 위해 사용되는 표준 프로토콜 $(128 \times 0.6 \mathrm{~mm}$ slice collimation, $0.28 \mathrm{sec}$ rotation time)을 적용하였고, 프로토 콜마다 선량 적용을 달리 하였다. 영상의 재구성은 $3 \mathrm{D}$

Workstation(Aquarius iNtuition Edition ver4.4, terarecon, USA; $0.6 \mathrm{~mm}$ Recon increment, B26f Heartview smooth ASA kernel)을 이용하였다. 선량변조는 좌심방으로부 터 CT 감약값의 표준편차에 따른 관전류를 차등 적용 하여 최적의 영상을 재현한 방식으로 CT 콘솔에 내장 되어 있는 기능을 적용하였다 ${ }^{[14]}$. 각 프로토콜 별 검사 조건은 다음과 같다.

\section{$2.1 \mathrm{DSCT} \mathrm{RGH}$ 스캔}

기본적으로 관전압 $120 \mathrm{kVp}$, 관전류 $400 \mathrm{~mA}$ 로 설정 하였고, 피치는 심박율에 따라 자동으로 설정하였다. 이는 심박율의 변동이 심한 경우와 부정맥(arrhythmia), 관상동맥 우회술을 시행한 경우에만 적용하였다. 관전 류 변조를 적용하지 않고 스캔하였으며, 심박동 이완 기 위상(diastole phase)의 65-75\%일 때, 수축기 위상 (systole phase)은 35-45\% 일 때만 $60 \%$ 선량을 적용하 였고, 나머지 위상에서는 선량의 $40 \%$ 로 설정하였다.

\section{2 선량변조 없는(not dose modulation, 이하 NDM) PGT}

관전압 $120 \mathrm{kVp}$, 관전류 $400 \mathrm{~mA}$ 로 설정하였고, 심 박동수가 60 회에서 75 회 사이인 경우 적용하였으며, 스캔 범위는 $12.89 \mathrm{~cm}$ 이었다. 선량은 이완기 위상 65-75\%일 때, 수축기 위상 35-45\%일 때만 전 선량을 적용하였다.

\section{3 선량변조(dose modulation 이하 DM) PGT}

관전압 $100 \mathrm{kVp}$, 관전류는 $400 \mathrm{~mA}$ 로 설정 후 dose modulation을 설정하였다. 선량은 이완기 위상 $65-75 \%$ 일 때, 수축기 위상 35-45\%일 때만 전 선량을 적용하 였다.

\subsection{FLASH spiral mode}

관전압 $120 \mathrm{kVp}$, 관전류 $400 \mathrm{~mA}$ 로 설정하였으며 변 조는 적용되지 않았다. FLASH 기법은 심박율이 60 회 이하, $\mathrm{SFOV}$ 가 $33 \mathrm{~cm}$ 까지만 제한적으로 스캔하였고, 피치 3.4로 고정하였고, 심장 이완기 후 $(60 \% \mathrm{R}-\mathrm{R}$ interval) 1 회 스캔을 시행하였다. 스캔 범위는 $12.00 \mathrm{~cm}$ 이었다.

\section{3. 유효선량의 산출}

유효선량의 산출은 CT 모니터 콘솔에 제시되는 선 량-길이곱(dose length product, 이하 DLP)을 이용하였다. $\mathrm{DLP}(\mathrm{mGy} \cdot \mathrm{cm})$ 에 ICRP 102 에서 권고하는 변환계수 $(0.014 \mathrm{mSv} \cdot \mathrm{mGy}-1 \cdot \mathrm{cm}-1)$ 를 곱하여 유효선량을 산출 하였다. 즉 유효선량 $(\mathrm{E})$ 은 다음 공식에 의해 계산된다. $\mathrm{E}=\mathrm{k} * \mathrm{DLP}, \quad$ 여기서 $\mathrm{k}$ 는 conversion factor 이다 ${ }^{[15,16]}$.

\section{4. 체질량지수에 따른 선량 적용}

$\mathrm{RGH}$ 스캔과 PGT 시 변조를 적용치 않는 스캔 시 대상자는 검사 전 키와 몸무게를 측정하여 체질량지 수를 산출하였고, 체질량지수가 $22 \mathrm{~kg} / \mathrm{m}^{2}$ 에서는 350 $\mathrm{mA}, 22-25 \mathrm{~kg} / \mathrm{m}^{2}$ 에는 $400 \mathrm{~mA}, 25-28 \mathrm{~kg} / \mathrm{m}^{2}$ 에는 420 $\mathrm{mA}, 28 \mathrm{~kg} / \mathrm{m}^{2}$ 이상에서는 450-500 mA를 적용하였다. 


\section{5. 암발생 생애귀속 위험 산출}

암 발생의 생애귀속위험(lifetime attributable risk, 이 하 LAR)의 평가는 미국의 전리 방사선 생물학적효과 위원회의 7차 보고서(biological effects of ionizing radiation committee VII, 이하 BEIR VII)를 활용하였다 ${ }^{[17]}$. 예를 들어 40 세 여성의 폐 등가선량이 $10 \mathrm{mSv}$ 이라면, BEIR VII의 모델에서 폐에 선량 $100 \mathrm{mSv}$ 가했을 때 40 세 여성의 폐암 발생에 대한 LAR은 100,000명 당 240 명이다. 따라서 $10 \mathrm{mSv}$ 선량에 대한 LAR은 10/100* $240 / 100000$ 이다.

\section{III. 결과}

\section{1. 임상적 특성}

전체 대상자 442명(남자 238명, 여자 204명)의 연령 은 평균 $61.5 \pm 13.5$ 세 이었고, 체질량지수의 평균은 $23.6 \pm 3.4 \mathrm{~kg} / \mathrm{m}^{2}$ 이었다(Table 1). 이들 중 SSCT는 RGH 로 128 명이었고, DSCT의 RGH는 56 명, NDM PGT 82 명, DM PGT 90명, FLASH는 86명이었다.

Table 1. Characteristics according to CT scan protocol

\begin{tabular}{|c|c|c|c|c|c|}
\hline & \multirow{2}{*}{$\begin{array}{c}\text { 64SSCT } \\
\text { PCH mode } \\
\text { (NOM) }\end{array}$} & \multicolumn{4}{|c|}{128 DSCT } \\
\hline & & $\begin{array}{l}\text { RCH mode } \\
\text { (NDM) }\end{array}$ & $\begin{array}{l}\text { PGT } \\
\text { (NOM) }\end{array}$ & $\begin{array}{l}\text { PGT } \\
\text { (OM) }\end{array}$ & $\begin{array}{l}\begin{array}{l}\text { FLASH } \\
\text { mode }\end{array}\end{array}$ \\
\hline No. of patients & 128 & 56 & 82 & 90 & 86 \\
\hline Male: female & $68: 60$ & $24: 32$ & $50: 32$ & $38: 52$ & $58: 28$ \\
\hline $\begin{array}{c}\text { Mean age } \\
\text { (yrs) }\end{array}$ & $60.2 \pm 11.6$ & $60.3 \pm 14.2$ & $61.5 \pm 16.8$ & $62.3 \pm 14.2$ & $62.9 \pm 11.1$ \\
\hline Mean weight $(\mathrm{kg})$ & $62.6 \pm 10.3$ & $69.1 \pm 15.6$ & $62.5 \pm 10.9$ & $60.6 \pm 13.4$ & $63.8 \pm 11.0$ \\
\hline Mean height (cm) & $161.9 \pm 9.4$ & $163.3 \pm 9.8$ & $160.8 \pm 9.7$ & $159.7 \pm 11.1$ & $165.0 \pm 8.5$ \\
\hline $\begin{array}{l}\text { Mean body mass } \\
\text { index }\left(\mathrm{kg} / \mathrm{m}^{2}\right)\end{array}$ & $23.4 \pm 3.2$ & $24.3 \pm 3.5$ & $23.7 \pm 3.2$ & $23.3 \pm 3.9$ & $23.0 \pm 3.2$ \\
\hline
\end{tabular}

\section{2. $\mathrm{SSCT}$ 와 $\mathrm{DSCT}$ 의 유효선량 비교}

64-절편 SSCT CA의 총 DLP 평균값은 936.5 $\mathrm{mGy-cm}$ 이었고, 이를 변환계수를 이용하여 유효선량 으로 산출한 결과 값은 $13.86 \mathrm{mSv}$ 이었다(Table 2). 128절편 DSCT에서 RGH mode의 총 DLP 평균값은 847.9 $\mathrm{mGy}-\mathrm{cm}$ 이었고, 유효선량은 $12.18 \mathrm{mSv}$ 이었다. 128-절 편 DSCT의 NDM PGT mode의 유효선량은 $6.14 \mathrm{mSv}$
였으며, DM PGT mode 유효선량은 $3.51 \mathrm{mSv}$ 이었다. 이완기 후 1 회 스캔하는 FLASH mode의 유효선량은 $1.26 \mathrm{mSv}$ 이었고, 각 그룹의 유효선량 평균은 유의한 차이가 있었다 $(\mathrm{p}<0.05)$.

Table 2. Effective dose from SSCT, DSCT scan protocol

\begin{tabular}{|c|c|c|c|c|c|}
\hline & \multirow{2}{*}{$\begin{array}{c}\text { 64-sl ice SSCT } \\
\begin{array}{c}\text { PGH mode } \\
\text { (NOM) }\end{array}\end{array}$} & \multicolumn{4}{|c|}{ 128-sl ice DSCT } \\
\hline & & $\begin{array}{l}\text { PGH mode } \\
\text { (NOM) }\end{array}$ & $\begin{array}{l}\text { PGT } \\
\text { (NOM) }\end{array}$ & $\begin{array}{l}\text { PGT } \\
(\mathrm{OM})\end{array}$ & $\begin{array}{l}\text { FLASH } \\
\text { mode }\end{array}$ \\
\hline CA CTDI (mGY) & $55.5 \pm 8.9$ & $43.0 \pm 24.3$ & $27.1 \pm 7.1$ & $15.0 \pm 4.5$ & $3.3 \pm 1.0$ \\
\hline CA DLP(mGy-cm) & $936.5 \pm 161.4$ & $840.9 \pm 357.2$ & $390.4 \pm 94.2$ & $211.9 \pm 62.1$ & $64.9 \pm 11.0$ \\
\hline $\begin{array}{l}\text { CA total DLP } \\
(m G y-c m)\end{array}$ & $989.7 \pm 162.1$ & $847.9 \pm 358.1$ & $400.8 \pm 94.3$ & $217.0 \pm 62.2$ & $70 . \pm 11.3$ \\
\hline $\begin{array}{l}\text { CA total } \\
\text { effective } \\
\text { dose(mSv) }\end{array}$ & $13.86 \pm 2.27 *$ & 12. $18 \pm 5.29 *$ & $6.14 \pm 1.34 *$ & $3.51 \pm 0.91 *$ & $\begin{array}{l}1.26 \pm \\
0.22 *\end{array}$ \\
\hline
\end{tabular}

\section{3. 체질량지수에 따른 선량 비교}

체질량지수 $22 \mathrm{~kg} / \mathrm{m}^{2}$ 미만에서 SSCT의 유효선량은 $12.43 \mathrm{mSv}$ 이었고, DSCT의 RGH 스캔에서는 $6.87 \mathrm{mSv}$ 이었다. 체질량지수가 $22.0-24.9 \mathrm{~kg} / \mathrm{m}^{2}$ 에서는 SSCT의 유효선량이 평균 $13.61 \mathrm{mSv}$ 이었고, DSCT의 RGH 스 캔에서는 $10.06 \mathrm{mSv}$, NDM PGT에서는 $6.29 \mathrm{mSv}$ 이었 다(Table 3). 각 스캔 프로토콜에서 체질량지수가 증가 함에 따라 유효선량도 높았다.

Table 3. Difference of effective dose from SSCT, DSCT scan protocol according to BMI(unit: mSv)

\begin{tabular}{|c|c|c|c|c|c|c|}
\hline & & \multirow{2}{*}{$\begin{array}{c}\text { 64-sl ice SSCT } \\
\text { RCH mode } \\
\text { (NOM) }\end{array}$} & \multicolumn{4}{|c|}{ 128-slice DSCT } \\
\hline & & & $\begin{array}{l}\text { RGH mode } \\
\text { (NOM) }\end{array}$ & $\begin{array}{l}\text { PGT } \\
\text { (NOM) }\end{array}$ & $\begin{array}{l}\text { PGT } \\
\text { (DM) }\end{array}$ & $\begin{array}{l}\text { FLASH } \\
\text { mode }\end{array}$ \\
\hline \multirow{4}{*}{$\begin{array}{c}\text { Body } \\
\text { mass } \\
\text { index } \\
\left(\mathrm{kg} / \mathrm{m}^{2}\right)\end{array}$} & 22 미만 & 12.43 & 6.87 & 5.30 & 3.12 & 1.15 \\
\hline & $22.0-24.9$ & 13.61 & 10.06 & 5.62 & 3.2 & 1.28 \\
\hline & $25.0-27.9$ & 15.46 & 15.54 & 6.29 & 3.9 & 1.28 \\
\hline & 28.0 이상 & 14.63 & 16.17 & 7.60 & 4.59 & 1.60 \\
\hline
\end{tabular}

\section{4. $\mathrm{LAR}$ 평가}

SSCT CA의 LAR은 남성 100,000 명 중 85 명에서 모 든 암이 발생할 수 있고, 여성은 100,000 명 중 78 명이 었다. DSCT에서 RGH의 LAR은 남성 51명, 여성 84명 이었고, NDM PGT mode의 LAR은 남성 33명, 여성 34 
명이었다. DM PGT mode의 LAR은 남성 17 명, 여성 19 명이었다(Table 4).

Table 4. Assessment of lifetime attributable risk of cancer incidence from SSCT and DSCT scan protocol

\begin{tabular}{|c|c|c|c|c|c|}
\hline & \multirow{2}{*}{$\begin{array}{c}64 \text { SSCT } \\
\text { RGH mode } \\
\text { (NDM) }\end{array}$} & \multicolumn{4}{|c|}{128 DSCT } \\
\hline & & $\begin{array}{l}\text { RCH mode } \\
\text { (NOM) }\end{array}$ & $\begin{array}{l}\text { PGT } \\
\text { (NOM) }\end{array}$ & $\begin{array}{l}\text { PGT } \\
\text { (OM) }\end{array}$ & $\begin{array}{l}\text { FLASH } \\
\text { mode }\end{array}$ \\
\hline \multicolumn{6}{|l|}{ All cancer } \\
\hline Males & $85(68-110)$ & $51(34-83)$ & $33(24-57)$ & $17(11-30)$ & $5(4-9)$ \\
\hline Females & $78(38-97)$ & $84(40-133)$ & $34(24-56)$ & $19(12-37)$ & $6(5-6)$ \\
\hline
\end{tabular}

이는 SSCT로 CA를 시행한 1,176명 중 1명에서 모든 암 발생 가능성이 있었고, DSCT로 RGH mode를 적용 한 1,960 명 중 1 명에서 모든 암 발생에 해당하였다. DSCT의 DM PGT로 시행한 5,882명 중 1명에서 모든 암 발생에 해당하였고, FLASH mode는 20,000명 중 1 명에 해당한다.

\section{$\mathrm{IV}$. 고찰}

CTCA 검사 시에는 장비의 성능, 환자의 심박율, 검 사 목적 등에 따라 다양한 CTCA 프로토콜이 개발되 어 있어 본 연구에서는 SSCT와 DSCT의 프로토콜별, 체질량지수별로 적용되는 환자 피폭선량을 비교해 보 았다.

CTCA 검사 시 불가피하게 적용되는 피폭선량을 줄 이기 위해 심장 전용 필터링 추가, 심장의 움직임 주 기에 따른 X-선 노출의 조절, 순차적 스캔을 이용한 전향적 심전도 동조화 등과 같은 방법이 현재 사용 중 이다 ${ }^{[18]}$. 또한 X-선관 회전속도가 64-절편 SSCT의 0.35 $\mathrm{sec}$ 에서 DSCT에서는 $0.28 \mathrm{sec}$ 로 감소되면서 시간분해능 을 $75 \mathrm{msec}$ 까지 향상시킬 수 있게 되어 심박율이 60 대 이하로 낮은 환자에게 있어서는 한 번의 심박동에 심 장 전체를 스캔 할 수 있는 FLASH mode도 개발되어 상용화 되었다.

먼저 Hausleiter 등은 절편 수가 많으면 방사선 선량 이 높아진다고 하였다 ${ }^{[1]}$. 이들은 16-절편과 64-절편 CT를 선량변조 기법을 사용하여 선량을 비교한 결과 에서 CTCA의 전체 유효선량은 16-절편 CT에서 $6.4 \pm 1.9 \mathrm{mSv}$ 이었고, 64-절편 $\mathrm{CT}$ 에서는 $11 \pm 4.1 \mathrm{mSv}$ 로
나타나 64-절편 CT의 유효선량이 약 2 배 높았다. 64-절 편 CT에서 선량이 높은 것은 16-절편 CT 보다 공간해 상도와 시간해상도가 더 높은 이유이다. Collimation이 16-절편의 $0.75 \mathrm{~mm}$ 에서 64-절편의 $0.6 \mathrm{~mm}$ 로 낮아지면 서 절편 간격이 좁아진 채로 화질을 유지하려면 검출 기 어레이에서 받아들이는 광자의 수가 높아야 한다. 이는 관전류를 높혀야 하기 때문에 유효선량이 높아 진다. 또한 스캔 길이, 화질, 갠트리 회전시간등도 선 량의 증가와 관련이 있다 ${ }^{[11]}$. 본 연구에서 64-절편 CT 와 128 -절편 $\mathrm{CT}$ 의 RGH mode의 유효선량은 각각 13.9 $\mathrm{mSv}, 12.2 \mathrm{mSv}$ 이었고, 128-절편 CT에서 더 낮았다. 이 는 128-절편 CT에서 시간 해상도와 공간해상도가 향 상 되었지만 갠트리 회전시간, 스캔 길이 및 횟수, 관 전류 등의 조절에 의한 원인으로 유추되며 추가적인 연구가 필요하리라 본다.

이전에 연구되어진 자료에 의하면, $\mathrm{RGH}$ 와 PGT mode에 따른 유효선량에서 RGH는 9.5-21.1 mSv 이었 고 $^{[7-10]}, \mathrm{RGH}$ 스캔 중에서도 수동조절 펄싱(pulsing manual), RGT 최소선량 펄싱(pulsing mindose) 등의 적용 에 의해서 RGT 펄싱 제거(pulsing off) 보다 선량을 49 $\%, 60 \%$ 까지 줄일 수 있다고 하였다 ${ }^{[18]}$. PGT 기법에 서 유효선량은 2.8-6.7 mSv 정도로 보고되고 있으며, $\mathrm{RGH}$ 기법과 비교 시 PGT 기법에서 68-87\% 선량을 감소시킬 수 있다고 하였다 ${ }^{[11,12]}$. 본 연구에서 DSCT에 서 $\mathrm{RGH}$ 의 유효선량은 $12.18 \mathrm{mSv}$ 이었고, 선량변조를 적용하지 않는 PGT의 유효선량은 $6.1 \mathrm{mSv}$, 선량변조 PGT는 $3.5 \mathrm{mSv}$ 이어서 DSCT에서는 RGH보다 PGT에 서 50-73\% 선량이 감소되었다. 또한 선량 변조 유무에 따라 선량이 2 배가량 차이가 났는데 선량변조를 적용 치 않는 경우 관전류를 $120 \mathrm{kVp}$ 로 적용하였고, 선량 변조 시 $100 \mathrm{kVp}$ 로 적용하여 직접적인 비교에는 다소 차이가 있을 수 있다. 하지만 기존의 보고에서 선량 변 조 기법은 선량을 약 $20 \%$ 까지 줄일 수 있다고 하였기 에 선량 감소의 효과는 있다고 판단되며, 선량 변조 기 법은 규칙적인 심장 리듬을 필요로 하기 때문에, 부정 맥이나 심박율의 변화가 심한 환자에게는 제한적으로 사용되기 때문에 신중하게 적용하여야 한다 ${ }^{[19]}$.

64-절편 SSCT의 경우 선량 변조 기법에서는 단일위 상만 얻을 수 있으므로 기능적 분석이 불가능하다는 단점이 있다 ${ }^{[12]}$. 선량변조 기법은 수축기말 위상이 이 
완기 동안의 어떤 재구성보다 나은 분석이 가능한데, 이는 심박동수가 65 beats/min 이상일 때는 이완기 말 위상이 너무 짧아 재구성을 할 수 없는 문제점이 발생 한다. 따라서 심전도 동기 선량변조 기법은 심박동수 가 65 beats/min 이상인 경우에는 적용할 수 없다 ${ }^{[20-22]}$.

심전도 펄싱(ECG-pulsing)은 선량 변조와 유사한 의 미인데, 심전도 펄싱 적용 시 유효 선량은 $9.4 \mathrm{mSv}$ 정 도이고, 심전도 펄싱을 적용하지 않을 경우는 14.8 $\mathrm{mSv}$ 정도 이었다 ${ }^{[20]}$. 선량의 감소를 위해서는 선량 변 조나 심전도 펄싱 기법을 적용하여야 하지만 환자의 상태나 심장 리듬 등을 고려하여 적용하여야 한다.

FLASH mode는 유효선량이 1-1.2 mSv 정도 밖에 되 지 않아 선량 감소의 면에서는 가장 적합하다. 하지만 3.4 이상의 높은 피치를 적용하여야 하고 심박율 60 회 이하, $\mathrm{SFOV}$ 가 $33 \mathrm{~cm}$ 까지만 제한적으로 스캔할 수 있 다. 이는 심장 수축한 이후에 긴 휴식기를 가지는 환 자에게 있어서는 관상동맥의 움직임이 없는 영상을 만들 수 있지만 심박동수가 높게 되면 심장이 수축한 후 R-R 간격이 짧아져서 다음 수축기까지 검사가 진 행되어 정확한 검사가 이루어 지지 않게 된다. 따라서 $\beta$ 차단제를 복용하여 심박수를 60 대로 낮춘 후 검사 를 시행하여야 한다 ${ }^{[18,23]}$.

선량을 줄이기 위한 가장 간단한 방법은 환자의 체 중을 적용하는 것인데, 날씬, 보통, 과체중 등의 3 가지 카테고리로 분류하여 각각의 파라메터를 지정하는 것 이다. 이 방법은 날씬한 환자에서는 전압을 $100 \mathrm{kV}$ 로 설정하기에 선량을 감소시킬 수 있다는 것이다 ${ }^{[10,24]}$. 본 연구에서도 체질량지수 $22 \mathrm{~kg} / \mathrm{m}^{2}$ 미만의 선량이 28 $\mathrm{kg} / \mathrm{m}^{2}$ 이상의 과체중 환자보다 $48 \%$ 정도 적었기에 검사 전 체질량지수의 측정이 필수적이고 체질량지수 에 따른 프로토콜 및 선량이 적용되어야 한다.

최근 심장 $\mathrm{CT}$ 에 대한 American Heart Association scientific statement에서는 Food and Drug Administration (FDA)의 발표를 인용하며 CT 스캔으로 인한 피폭선량 이 $10 \mathrm{mSv}$ 이면 대략 2,000 명 중 1 명이 치명적 암 발생 가능성이 있는 것으로 보고하였다 ${ }^{[13]}$. 특히 Einstein 등 은 심장 CT를 한 20 세 여성의 143 명 중 1 명에서 암 발 생의 위험이 있다고 경고하고 있고 ${ }^{[25]}$, 타 연구에서도 CT 검사가 암 발생과 관련이 있음을 보고하였다 ${ }^{[26]}$.
본 연구에서는 BEIR 보고서를 인용하여 암 발생 가능 성을 살펴보니, SSCT의 RGH mode에서 1,176명 중 1 명 에서 모든 암 발생 가능성이 있었고, DSCT의 PGT 변 조로 시행한 5,882명 중 1 명에서 모든 암 발생에 해당 하였다. 따라서 심장 CT 검사는 선량이 적더라도 암 발생에 중요한 원인이 될 수 있음을 인지하여야 한다.

본 연구의 제한점은 SSCT에서도 심장 $\mathrm{CT}$ 검사 프 로토콜이 다양하나 RGH mode의 자료만 이용하여 유 효선량을 산출하였으므로 SSCT의 심장 CT 전체의 선 량으로 보편화하기는 제한적이다. 또한 유효선량의 산 출 시 DLP 값에다 유효선량 변환계수를 곱하여 유효 선량을 계산하였으므로 실제 환자의 유효선량과는 다 소 차이가 있을 수 있다. 추후에 장비 및 제조사 별로 차이가 있는 심장 CT 프로토콜에 따른 환자 선량에 대한 광범위한 조사가 추가적으로 필요하다고 본다.

\section{$\mathrm{V}$. 결론}

64-절편 SSCT와 128-절편 DSCT를 이용한 심장 CT 에서 검사 프로토콜에 따른 환자선량의 차이가 있었 다. SSCT의 RGH mode 보다 DSCT에서의 RGH mode 의 유효선량이 유의하게 낮았고, DSCT에서도 RGH mode 보다 PGT 기법의 선량이 낮았다. 또한 선량 변 조 기법을 적용한 검사가 더 낮았으며, FLASH spiral mode는 심박동수가 일정하고, 60 회 이하에 제한적으 로 사용되지만 피폭선량의 경감 효과는 가장 높았다. 체질량지수에 따라서도 선량을 달리 적용하며 과체중 보다 저체중의 체질량지수에서 선량이 낮게 적용되었 다. 따라서 환자의 상태와 심박동수, 장비의 기능 등을 신중히 고려하여 검사를 시행하여야 하며, 관상동맥조 영 CT 검사는 암발생 귀속위험과 관련성이 있음을 인 지하여, 환자선량을 줄이기 위해 RGH보다 PGT, $\mathrm{FLASH}$ 등의 프로토콜을 적용하는 것이 필요하다.

\section{Reference}

[1] Raff GL, Gallagher MJ, O'Neill WW and Goldstein JA, "Diagnostic accuracy of noninvasive coronary angiography using 64-slice spiral computed tomography", J Am Coll Cardiol, Vol. 46, No. 3, pp.552-557, 2005.

[2] Mollet NR, Cademartiri F, Carlos AG, and et al. "High-resolution spiral computed tomography coronary 
angiography in patients referred for diagnostic conventional angiography", Circulation, Vol. 112, pp.2318-2323, 2005.

[3] Brenner DJ, Hall EJ, "Computed tomography-an increasing source of radiation exposure", N Engl J Med, Vol. 357, pp.2277-2284, 2007.

[4] Achenbach S, Ropers D, Kuettner A, and et al. "Contrast-enhanced coronary artery visualization by dual-source computed tomography-initial experience", Eur J Radiol, Vol. 57, pp.331-335, 2006.

[5] Johnson TR, Konstantin N, Wintersperger BJ, et al. "Dual-source CT cardiac imaging: initial experience", Eur Radiol, Vol. 16, pp1409-1415, 2006.

[6] H Scheffel, H Alkadhi, A Plass, and et al. "Accuracy of dual-source CT coronary angiography: first experience in a high pre-test probability population without heart rate control", Eur Radiol Vol. 16, pp.2739-2747, 2006.

[7] Francone M, Napoli A, Carbone I, and et al. "Noninvasive imaging of the coronary arteries using a 64-row multidetector CT scanner: initial clinical experience and radiation dose concerns", Radiol Med, Vol. 112, No. 1, pp31-46, 2007.

[8] McCollough CH, Primak AN, Saba O, and et al. "Dose performance of a 64-channel dual-source CT scanner", Radiology Vol. 243, No .3, pp.775-784, 2007.

[9] S Baumuller, S Leschka, L Desbiolles, and et al. "Dual-source versus 64-section CT coronary angiography at lower heart rates: Comparison of accuracy and radiation dose", RSNA, Radiology, Vol. 253, No. 1, pp.56-64, 2009.

[10] Hausleiter J, Meyer T, Hadamitzky M, and et al. "Radiation dose estimates from cardiac multislice computed tomography in daily practice: impact of different scanning protocols on effective dose estimates", Circulation, Vol. 113, pp.1305-1310, 2006.

[11] Stolzmann P, Scheffel H, Schertler T, and et al. "Radiation dose estimates in dual-source computed tomography coronary angiography", Eur Radiol, Vol. 18, No. 3, pp.592-599, 2008.

[12] JP Earls, EL Berman, BA Urban, and et al. "Prospectively gated transverse coronary CT angiography versus retrospectively gated helical technique: Improved image quality and reduce radiation dose", Radiology, Vol. 246, No. 3, pp.1081-1086, 2008.

[13] US Food and Drug Administration, Center for Devices and Radiological Health. "Whole body scanning using computed tomography(CT): what are the radiation risks from CT?", http://www.fda.gov/ cdrh/ct/risks.html.
[14] Gham Hur, Seong Wan Hong, Su Young Kim, and et al. "Uniform image achieved by tube current modulation using SD of attenuation in coronary CT angiography", AJR, Vol. 189, pp.188-196, 2007.

[15] ICRP, "Managing Patient Dose in Multi-detector Computed Tomography", ICRP publication 102, 2007.

[16] G Bongartz, SJ Golding, AG Jurik, M Leonardi, EvP van Meerten, J Geleijns, and et al. "European guidelines on quality criteria for computed tomography", EUR 16262, 2000. http://www.drs.dk/guidelines /ct/quality

[17] Committee to Assess Health Risks from Exposure to low levels of Ionizing Radiation, National Research Council of the National Academies. Health risks from Exposure to Low Levels of Ionizing Radiation, BEIR VII Phase 2. Washington, DC: The National Academies Press, 2006

[18] 이대규, 김문찬, 방성호, 한동균. Dual source CT에서 High-pitch Cardiac scan mode를 이용한 관상동맥 검사의 유용성. 대한전산화단층기술학회지. Vol. 12, No. 1, p25-33, 2010.

[19] JF Paul, and HT Abada, "Strategies for reduction of radiation dose in cardiac multislice CT", EUR Radiol, Vol. 17, pp.2028-2037, 2007.

[20] Poll LW, Cohnen M, Brachten S, Ewen K, and Modder U, "Dose reduction in multi-slice CT of the heart by use of ECG-controlled tube current modulation ("ECG pulsing"): phantom measurements", Rofo, Vol. 174, No. 12, pp.1500-1505, 2002.

[21] Leschka S, Wildermuth S, Boehm T, and et al. "Noninvasive coronary angiography with 64-section CT: effect of average heart rate and heart rate variability on image quality", Radiology, Vol. 241, No. 2, pp.378-385, 2006.

[22] Leschka S, Husmann L, Desbiolles LM, and et al. "Optimal image reconstruction intervals for non-invasive coronary angiography with 64-slice CT", Eur Radiol, Vol. 16, No. 9, pp.1964-1972, 2006.

[23] S Achenbach, T Goroll, M Seltmann, and et al. "Detection of coronary artery stenosis by low-dose, prospectively ECG-triggered, high-pitch spiral coronary CT angiography", JACC, Cardiovascular imaging, Vol. 4, No. 4, pp.211, 2011.

[24] Jung B, Mahnken AH, Stargardt A, and et al. "Individually weight-adapted examination protocol in retrospectively ECG-gated MSCT of the heart", Eur Radiol Vol. 13, pp.2560-2566, 2003

[25] Einstein AJ, Henzlova MJ, and Rajagopalan S, "Estimating risk 
of cancer associated with radiation exposure from 64-slice computed tomography coronary angiography", JAMA, Vol. 298, No. 3, pp.317- 323, 2007.

[26] AC Weustink, NR mollet, LA Neefjes, and et al. "Preserved Diagnostic Performance of Dual-Source CT coronary Angiography with Reduced Radiation Exposure and Cancer Risk", Radiology, Vol. 252, No. 1, pp.53-60, 2009. 